\title{
M2 macrophages promote myofibroblast differentiation of LR-MSCs and are associated with pulmonary fibrogenesis
}

\author{
Jiwei Hou ${ }^{1,2}$, Jingyan Shi ${ }^{1,2}$, Ling Chen ${ }^{1,2}$, Zhongyang Lv ${ }^{1,2}$, Xiang Chen ${ }^{1,2}$, Honghui Cao ${ }^{1,2}$, Zou Xiang ${ }^{3}$ and
} Xiaodong $\operatorname{Han}^{1,2^{*}}$

\begin{abstract}
Background: Idiopathic pulmonary fibrosis (IPF) is a devastating disease characterized by the histopathological pattern of usual interstitial pneumonia and is associated with a high mortality rate. Recently, lung resident mesenchymal stem cells (LR-MSCS) have been identified as an important contributor to myofibroblast activation in pulmonary fibrosis. Macrophages are also believed to play a critical role in pulmonary fibrosis. However, the underlying connections between LR-MSCs and macrophages in the pathogenesis of pulmonary fibrosis are still elusive.
\end{abstract}

Methods: In this study, we investigated the interaction between LR-MSCs and macrophages using a bleomycin-induced mouse pulmonary fibrosis model and a coculture system.

Results: Here, we show that blocking pulmonary macrophage infiltration attenuated bleomycin-induced pulmonary fibrosis. In addition, as determined by flow cytometry, we discovered that the recruited macrophages in fibrotic lungs of bleomycin-treated mice were mainly M2 macrophages. In particular, we found that M2, rather than M1 macrophages, promoted myofibroblast differentiation of LR-MSCS. Moreover, we demonstrated that suppression of the Wnt/ $\beta$-catenin signaling pathway could attenuate myofibroblast differentiation of LR-MSCs induced by M2 macrophages and bleomycin-induced pulmonary fibrosis. Tissue samples from IPF patients confirmed the infiltration of M2 macrophages and activation of Wnt/ $\beta$-catenin signaling pathway.

Conclusion: In summary, this study furthered our understanding of the pulmonary fibrosis pathogenesis and highlighted M2 macrophages as a critical target for treating pulmonary fibrosis.

Keywords: Idiopathic pulmonary fibrosis (IPF), M2 macrophages, Lung resident mesenchymal stem cells (LR-MSCs), Myofibroblast differentiation

\section{Background}

Idiopathic pulmonary fibrosis (IPF) is one of the most common forms of interstitial lung diseases characterized by the deposition of interstitial collagen and other extracellular matrix, leading to dyspnea, cough, impaired lung function, and death [1-3]. IPF has a poor prognosis, with a median survival of approximately 3 years from the time of diagnosis [4], and the prevalence of IPF rises

\footnotetext{
* Correspondence: hanxd@nju.edu.cn

${ }^{1}$ Immunology and Reproduction Biology Laboratory \& State Key Laboratory of Analytical Chemistry for Life Science, Medical School, Nanjing University, Hankou Road 22, Nanjing 210093, China

${ }^{2}$ Jiangsu Key Laboratory of Molecular Medicine, Nanjing University, Nanjing 210093, China

Full list of author information is available at the end of the article
}

dramatically with age. However, therapeutic options to alter the course of this disease remain lacking. As the etiology of IPF is unknown, it is highly desirable to unravel the mechanisms underlying the pathogenesis of pulmonary fibrosis, which may facilitate the development of novel clinical strategies.

In pulmonary fibrosis, the accumulation of fibroblasts and $\alpha-\mathrm{SMA}^{+}$myofibroblasts is largely responsible for the production of collagen within alveolar structures [5]. Therefore, defining the cellular origin of these cells is critical for understanding the pathobiology of pulmonary fibrosis. Recent evidence suggests that lung resident mesenchymal stem cells (LR-MSCs) are precursors of myofibroblasts and also can be induced to differentiate

(C) The Author(s). 2018 Open Access This article is distributed under the terms of the Creative Commons Attribution 4.0 International License (http://creativecommons.org/licenses/by/4.0/), which permits unrestricted use, distribution, and 
into many other cell types that may participate in lung repair or contribute to the development of pulmonary diseases [6, 7]. Therefore, the roles and fate of LRMSCs during development in pathological conditions in the lung have attracted substantial attention [8-10]. In particular, the differentiation of LR-MSCs is sensitive to the microenvironment to which these cells are exposed [11].

Inflammatory responses are associated with the development of IPF and inflammatory cells, especially macrophages, that play an important role in the regulation of microenvironment after lung injury [12]. Macrophages are present in virtually all the tissues of the body and play crucial roles in both acute and chronic pulmonary pathologies including cytotoxicity and fibrosis [13-15]. Macrophages are highly plastic and assume their functional phenotype dependent on the inflammatory signals they encounter in the tissue microenvironment $[16,17]$. Macrophages can be classified as M1 or M2 subtypes depending on their functional phenotypes [18], although there is a continuum of macrophage polarization beyond the simplified, discrete, in vitro-based classification system. The classically activated macrophages (i.e. M1 macrophages) induced by lipopolysaccharide (LPS), are characterized by production of mediators aimed at eliminating foreign materials and debris $[19,20]$. The alternatively activated macrophages (M2 macrophages) which are induced by IL- 4 are known to release mediators that down regulate the inflammatory response and promote the resolution of injury and tissue repair [21, 22]. Importantly, M1/M2 macrophage polarization has been associated with the progression of fibrotic diseases [23, 24]. However, the underlying connections between LR-MSCs and macrophage polarization in the pathogenesis of pulmonary fibrosis are still elusive.

The Wnt/ $\beta$-catenin signaling is an evolutionarily conserved signal pathway that has been demonstrated to play a crucial role in cell fate decision of mesenchymal stem cells in fibrotic disease $[25,26]$. This pathway includes a group of ligands that act as intercellular signaling molecules, and importantly, the induction of Wnt ligands by macrophages has been reported to be critical for stem cell regeneration following damage [27, 28]. Nevertheless, the possible involvement of the macrophage phenotype in the activation of Wnt signaling pathways in LR-MSCs has not been investigated.

In the current study, we first investigated the effect of recruited macrophages on the development of bleomycin-induced pulmonary fibrosis. Next, we evaluated the kinetics of in vivo macrophage polarization in the pathogenesis of pulmonary fibrosis. We also examined the effects of macrophages with various activation phenotypes on the differentiation of LR-MSCs. Importantly, the roles of Wnt/ $\beta$-catenin signaling pathways in myofibroblast differentiation of LR-MSCs and progression of pulmonary fibrosis were examined.

\section{Materials and methods Chemicals}

Bleomycin was purchased from Nippon Kayaku (Tokyo, Japan). Clodronate and control liposome were purchased from clodronateliposomes.org (Vrije University, Netherlands). Enzyme-linked immunosorbent assay (ELISA) kits for Wnt7a was purchased from Cusabio (no. CSB-EL026141MO, Wuhan, China). Salinomycin (a specific Wnt/FZD/LRP5 complex inhibitor) was purchased from Medchemexpress (no. HY-15597, Monmouth Junction, NJ). Antibodies used in this study were listed in Additional file 1: Table S1.

\section{Animals and treatment}

Male C57BL/6 (9-10 weeks old) mice were purchased from the Medical School of Yangzhou University (Yangzhou, China). All mice were maintained under standard conditions with free access to water and laboratory rodent food. Bleomycin-induced mouse pulmonary fibrosis model was established as described by us previously [29]. Fifty microliters of clodronate or control liposome was injected intratracheally every three days starting two days before the injection of bleomycin, until the end of the experiment. Mice were sacrificed 21 days after bleomycin instillation.

To evaluate the effect of $\mathrm{Wnt} / \beta$-catenin signaling on bleomycin-induced pulmonary fibrosis, we injected mice with salinomycin, a small-molecule Compound that specifically inhibits Wnt/ $\beta$-catenin, as previously described [30]. Specifically, 7 days after administration with bleomycin, mice were intraperitoneally administered with $5 \mathrm{mg} / \mathrm{kg}$ salinomycin or vehicle three times a week. In this study, mice were randomly divided into four groups $(n=12)$. Group 1 received saline treatment; group 2 received $5 \mathrm{mg} / \mathrm{kg}$ salinomycin; group 3 received $5 \mathrm{mg} / \mathrm{kg}$ bleomycin and vehicle; and mice in group 4 received $5 \mathrm{mg} / \mathrm{kg}$ bleomycin and 5 $\mathrm{mg} / \mathrm{kg}$ salinomycin. Mice were sacrificed 21 days after bleomycin instillation. Mouse lungs were obtained for the analysis of immunofluorescence analyses, q-PCR and western blotting.

All procedures carried out on animals were approved by the Animal Care and Use Committee of Nanjing University under the animal protocol number SYXK (Su) 2009-0017.

\section{Cell line culture and macrophage polarization}

RAW 264.7 macrophage-like cells, obtained from the cell bank of Chinese Academy Sciences (Shanghai, China), were cultured as described previously [31]. RAW 264.7 cells in exponential growth were plated at a density of $1 \times 10^{5}$ cells $/ \mathrm{ml}$. After overnight incubation, cells were treated with $10 \mathrm{ng} / \mathrm{ml}$ LPS (Sigma-Aldrich no. L2880, St. Louis, MO) or $10 \mathrm{ng} / \mathrm{ml}$ IL-4 (Peprotech no. AF-214-14, Rocky Hill, NJ) for 
$24 \mathrm{~h}$ to induce M1 and M2 macrophage differentiation, respectively [32-34].

\section{Indirect coculture system}

Isolation of LR-MSCs was performed as previously reported [35]. Indirect coculture system was established using cell culture inserts ( $0.4 \mathrm{~mm}$ PET, $4.5 \mathrm{~cm}^{2}$, Millipore). LR-MSCs and RAW macrophages were each plated at $1 \times 10^{5}$ cells $/ \mathrm{ml}$. LR-MSCs were plated in the lower chamber and RAW macrophages were plated in the upper chamber. After $72 \mathrm{~h}$ coculture, inserts were removed and LR-MSCs were harvested for western blotting and immunofluorescence analyses. Furthermore, for assessing the regulation of $\mathrm{Wnt} / \beta$-catenin signaling, salinomycin was added to the medium of the cocultured LR-MSCs at a concentration of $1 \mu \mathrm{M}$ in DMSO, at the beginning of coculture. DMSO was added in the control culure.

\section{RNA interference}

Commercially available siRNA for the mouse Wnt7a $(\mathrm{sc}-41,115)$ gene and nonspecific control siRNA $(\mathrm{sc}-37,007)$ were purchased from Santa Cruz Biotechnology. Transient transfection was carried out as detailed previously [36].

\section{Flow cytometric analysis}

To determine the macrophage subtypes in fibrotic lungs, lower right lungs were minced with fine scissors, and enzymatically digested with $0.1 \%$ type I collagenase (Sigma no. C0130) for $1 \mathrm{~h}$ at $37^{\circ} \mathrm{C}$ with gentle agitation every $20 \mathrm{~min}$. The single cell suspension was refiltered through a $40-\mu \mathrm{m}$ nylon mesh after digestion to remove connective tissue, after which the cells were washed with D-Hanks and collected by centrifugation by $300 \times \mathrm{g}$ for 5 min. Cells were incubated with PE-conjugated F4/80 antibodies or APC-conjugated CD206. Flow cytometry was performed on a FACS CaliburTM flow cytometer and the data were analyzed using Paint-A-Gate software (Becton Dickinson).

In addition, flow cytometric analyses were used to determine the macrophage polarization in vitro. RAW 264.7 cells after stimulation were incubated with fluorescent antibodies at $37^{\circ} \mathrm{C}$ for $40 \mathrm{~min}$ in the dark followed by two washes with PBS. The antibodies used were: PE-conjugated anti-CD68, PE-conjugated anti-CCR7, and APC-conjugated anti-CD206.

\section{Human lung tissue}

Surgical biopsy specimens from IPF lung tissue samples were obtained from Nanjing Drum Tower Hospital. Patient controls were selected to be similar in age to IPF patients with nonfibrotic lung disorders. Lung biopsy samples were processed by standard techniques for western blotting, Immunohistochemistry, and immunofluorescence analyses. All protocols concerning the use of patient samples in this study were approved by the Ethics Committee of Nanjing Drum Tower Hospital.

\section{Immunohistochemistry, hematoxylin-eosin (H\&E) and Masson's trichrome stain}

Immunohistochemistry was performed on 4- $\mu \mathrm{m}$, paraffinembedded lung tissue and mounted on polylysine-coated slides. The slides were cleared of paraffin and subjected to antigen retrieval $(10.2 \mathrm{mM}$ sodium citrate, $0.05 \%$ Tween 20 , $\mathrm{pH}$ 6.0, $10 \mathrm{~min})$. Next, quenching of endogenous peroxidase activity was achieved by incubation with $3 \%(v / v) \mathrm{H}_{2} \mathrm{O}_{2}$ for $10 \mathrm{~min}$, followed by incubation with rat anti-Sca-1, rat anti-F4/80, rabbit anti-iNOS, or rabbit anti-CD206 at $4{ }^{\circ} \mathrm{C}$ overnight. The DAB Substrate System (DAKO) was used to reveal the immunohistochemical staining. In addition, the slides were stained with $H \& E$ for structured observation, or with Masson's trichrome stain for detection of collagen deposits according to the instructions by the manufacturer (KeyGen no. KGA224/KGMST-8003, Nanjing, China).

\section{Immunofluorescence}

Immunofluorescence analyses of LR-MSCs or lung tissues were performed as described previously [37]. The following primary antibodies were employed: rat anti-Sca-1, mouse anti- $\alpha$-smooth muscle actin ( $\alpha$-SMA), rabbit anti-collagen I, mouse anti-CD206, rabbit anti-F4/80, and rabbit antiWnt7a. Alexa Fluor 488-conjugated goat anti-mouse antibody, Alexa Fluor 488-conjugated goat anti-rat antibody, Alexa Fluor 594-conjugated goat anti-mouse antibody and Alexa Fluor 594-conjugated goat anti-rabbit antibody (Invitrogen no.A-11001, A-11006, A-11032, and A-11037, respectively, Carlsbad, CA, 1:200 dilution) was used as a secondary antibody. Nuclei were stained with 4',6-diamidino-2-phenylindole (DAPI) (Sigma no. D9542). The images were observed under confocal fluorescence microscope (Olympus, Tokyo, Japan) with the Z-stack technique (0.8 $\mu \mathrm{m} /$ layer).

\section{Quantitative real-time polymerase chain reaction (Q-PCR)}

The RNA extraction was performed as previously described [38]. The sequences of primer pairs used in this assay are shown in Additional file 1: Table S2. Q-PCR was conducted by amplifying $20 \mu \mathrm{l}$ of diluted cDNA with the SYBR Green Q-PCR kit (Vazyme no.Q711-02, Nanjing, China) on an ABI ViiA 7 Q-PCR System (Applied Biosystems, Waltham, MA). Each sample was run in triplicate and PCR reactions without the addition of the template were used as blank controls. The relative quantification of the expression of the target genes was measured using glyseraldehyde-3-phosphate dehydrogenase (GAPDH) mRNA as an internal control. 


\section{Western blotting, coimmunoprecipitation (co-IP) and ELISA analyses}

Proteins were purified from either LR-MSCs or lung tissues. Western blotting analyses of cellular lysates were performed as previously described [39]. Cytosolic and nuclear extracts were prepared with nuclear and cytosolic extraction reagent kit (Invent Biotechnologies no.SC-003, Eden Prairie, MN) according to the manufacturer's instructions. Proteins were separated using 12\% SDS-polyacrylamide gel electrophoresis and were electrophoretically transferred to polyvinylidene fluoride (PVDF) membranes using standard procedures. Next, these plots were incubated overnight at $4{ }^{\circ} \mathrm{C}$ with rabbit anti-collagen I, rabbit anti- $\beta$-catenin, mouse anti- $\alpha$ -SMA, rabbit anti-Wnt7a, mouse anti-Frizzled-1, rabbit anti-iNOS, mouse anti-CD206, rabbit anti-Histone $\mathrm{H} 3$, rabbit anti-Sca-1, and rabbit anti-GAPDH. Horseradish peroxidase-conjugated goat anti-rabbit/mouse IgG (Boster no. BA1056/BA1050, Wuhan, China, 1:10,000 dilution) was used as a secondary antibody. Co-IP was performed by using $800 \mu \mathrm{g}$ of protein from lysates of LR-MSCs. AntiFrizzled-1 antibody was used as the precipitating antibody to isolate Frizzled-1 from lysates, followed by western blotting to identify whether Wnt7a can bind to Frizzled-1 on the membrane using anti-Wnt7a antibody. Blots were re-probed with anti-Frizzled-1antibody to confirm equal protein loading. Co-IP with mouse IgG served as a negative control. Wnt7a levels in cell supernatant were measured by ELISA kits according to the manufacturer's instructions.

\section{Statistical analyses}

SPSS 18.0 (SPSS, Chicago, IL) was used for statistical analysis. The data are presented as mean values \pm SD. The Student's t test was used for paired comparisons.

For the comparison of three or more groups, one-way ANOVA was used for the comparison, which was followed by Duncan's post hoc test. A $p$ value of less than 0.05 was considered statistically significant.

\section{Results}

\section{The myofibroblast differentiation of LR-MSCs is closely} correlated with pulmonary fibrogenesis

Following intratracheal spray of bleomycin, the expression of $\alpha$-SMA and collagen I was increased (Additional file 1: Figure S1), suggesting the occurrence of fibrosis. We next investigated the colocalization of mesenchymal stem cells and mesenchymal markers. Colocalization of Sca-1 and myofibroblast marker $\alpha$-SMA in the endothelium layer of pulmonary arterioles and microcapillary vessels was observed at day 21 after bleomycin injection (Fig. 1a). Specific overlay of $\mathrm{Sca}-1^{+} / \alpha-\mathrm{SMA}^{+}$cells was examined by z-stack analysis [40] (Fig. 1c). In addition, the above results were also confirmed in lung tissues of IPF patients (Fig. $1 \mathrm{~b}$ and d). Our findings suggest that myofibroblast differentiation of LR-MSCs may be a source of myofibroblast accumulation in pulmonary fibrogenesis.

\section{Macrophage infiltration contributes to the development of bleomycin-induced pulmonary fibrosis}

Although inflammatory macrophages have been shown to play an essential role in the progression of fibrosis and tissue remodeling [41, 42], the exact mechanism remains largely unknown. To elucidate the mechanisms by which the recruited macrophages participate in the development of pulmonary fibrosis, we first performed immunostaining for $\mathrm{F} 4 / 80$, a specific marker for macrophages, on lung tissues from saline or bleomycin-treated mice. We found a robust increase in $\mathrm{F} 4 / 80^{+}$cells in mouse lungs following bleomycin treatment (Fig. 2a and b). Thus, these data suggest that the development of bleomycin-induced pulmonary fibrosis is accompanied by robust macrophage infiltration.

To explore whether the recruited macrophages may affect the development of pulmonary fibrosis, we tried to chemically deplete macrophages by clodronate, a myeloid-specific ablating liposome that induces apoptosis of macrophages [43, 44]. Clodronate was injected intratracheally every three days starting two days before the injection of bleomycin (Fig. 2c). Our data demonstrated a marked decline in $\mathrm{F} 4 / 80^{+}$cells in the clodronate-treated mice. We quantified the frequency of $\mathrm{F} 4 / 80^{+}$cells in the dissociated whole lung tissue cells by flow cytometry and found that macrophages decreased from $19.2 \pm 3.7 \%$ of the total lung cells in the control mice (injected with control liposome) to $8.6 \pm 0.7 \%$ of the total lung cells in clodronate-treated mice (Fig. 2d). In addition, the mRNA levels of the inflammatory factors (i.e. IL-1 $\beta$, IL- 6 and TNF- $\alpha$ ) were decreased in mouse lungs after clodronate treatment (Additional file 1: Figure S2). Taken together, clodronate efficiently reduced the recruitment of inflammatory macrophages in bleomycin-treated mice.

Next, we wanted to determine whether this reduction in inflammatory macrophages may affect the development of bleomycin-induced pulmonary fibrosis. We found that treatment with clodronate attenuated the severity of pulmonary fibrosis confirmed by morphological changes assessed by H\&E and Masson's trichrome staining (Fig. 2e). Moreover, the expression of collagen I and $\alpha$-SMA, the major markers of pulmonary fibrosis, was profoundly decreased in clodronate-treated mice (Fig. 2f and g). These data suggest that infiltrating macrophages exacerbated bleomycin-induced pulmonary fibrosis.

\section{Infiltrated macrophages in fibrotic lungs are mainly M2 macrophages}

As macrophages demonstrate two distinct functional phenotypes (M1 and M2 macrophages) that are responsible for various pathophysiological processes, we thus 


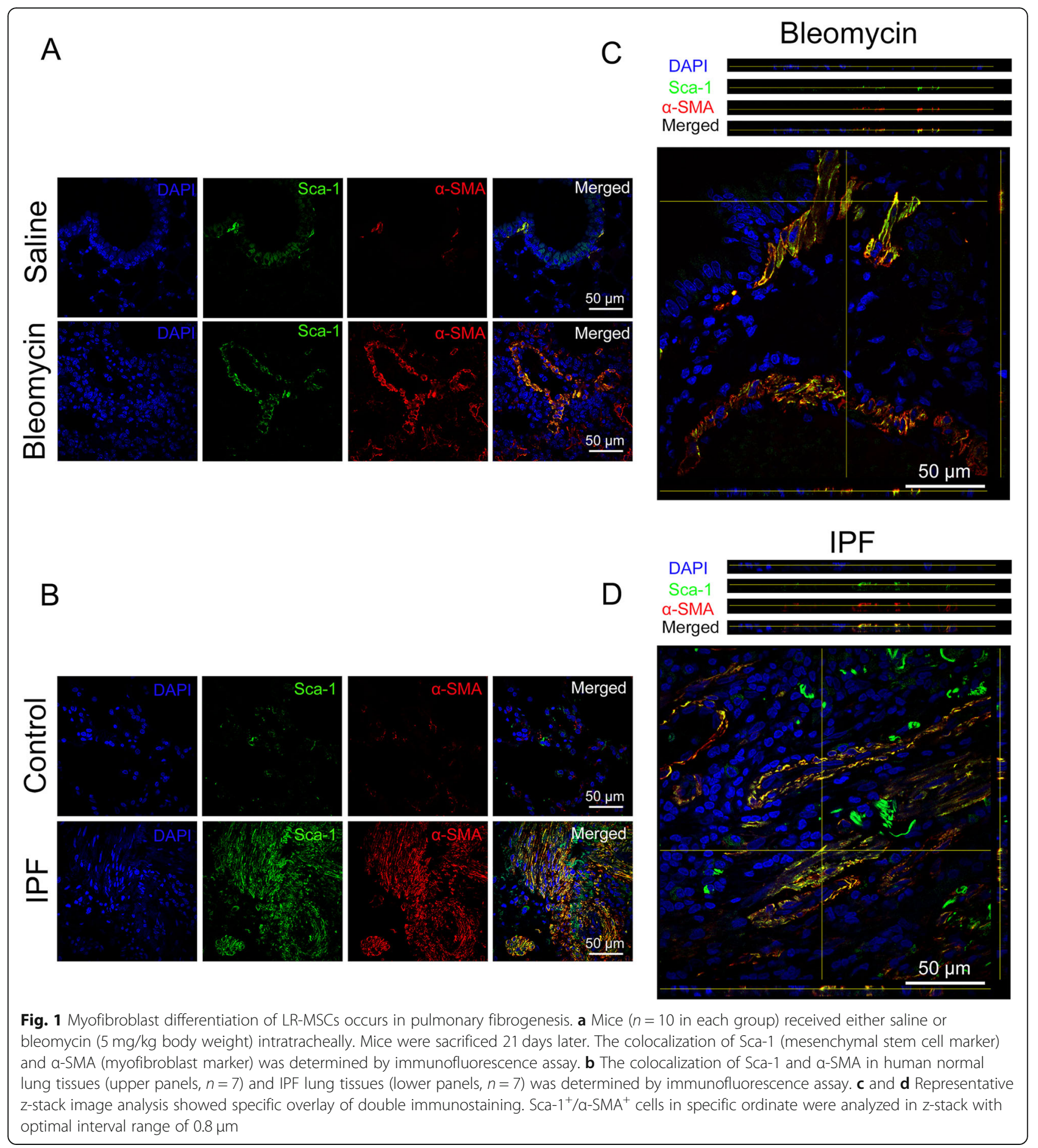

evaluated the kinetics of in vivo macrophage polarization in mice following intratracheal injection of bleomycin. We first examined the mRNA expression of the primary M1 and M2 polarization markers including inducible nitric oxide synthase (iNOS) and arginase (Arg-1) in lung tissues of bleomycin-treated mice. At 14 days postinjection, pulmonary macrophages were strongly M1 polarized, as they expressed high levels of iNOS mRNA and very low levels of Arg-1 mRNA (Fig. 3a). At 21 days postinjection, the overall polarization of macrophages shifted to M2 as Arg-1 expression was increased and iNOS expression was decreased (Fig. 3a). Next, we confirmed our finding using flow cytometric analysis of surface markers that could differentiate M2 and M1 macrophages. Our results demonstrated that the frequency of $\mathrm{CD}_{20} 6^{+} \mathrm{M} 2$ macrophages in the $\mathrm{F} 4 / 80^{+}$cell population increased to 


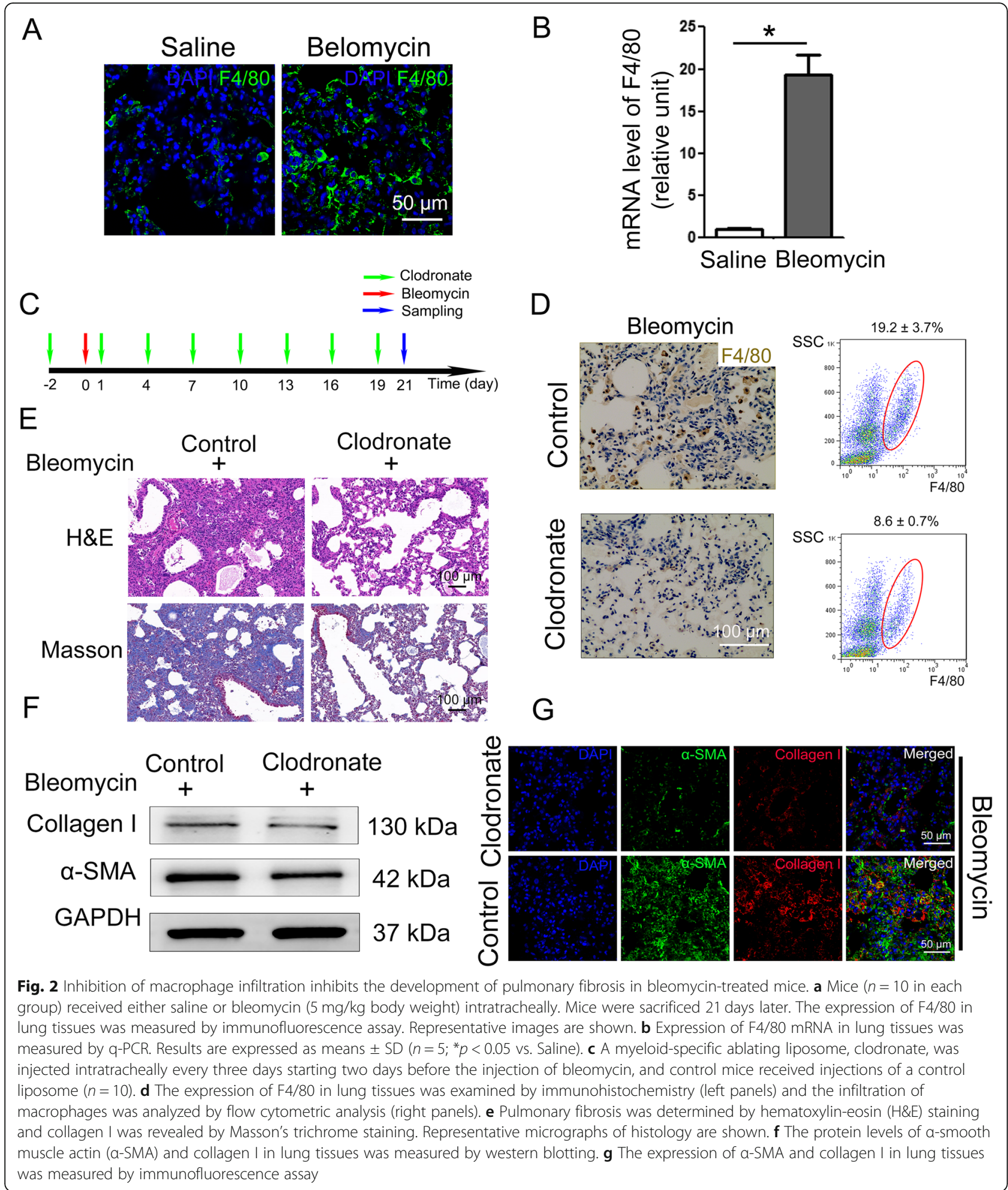

$(56.4 \pm 2.3 \%)$ macrophages $\left(\mathrm{F} 4 / 80^{+}\right)$in fibrotic lungs 21 days after treatment (Fig. 3b). These data confirmed the predominance of the recruited macrophages in fibrotic lungs were M2 macrophages.
M2 macrophages promote myofibroblast differentiation of LR-MSCs through the Wnt/ $\beta$-catenin signaling pathway The differences between recruited macrophage subsets suggest that M1 and M2 macrophages may have different 


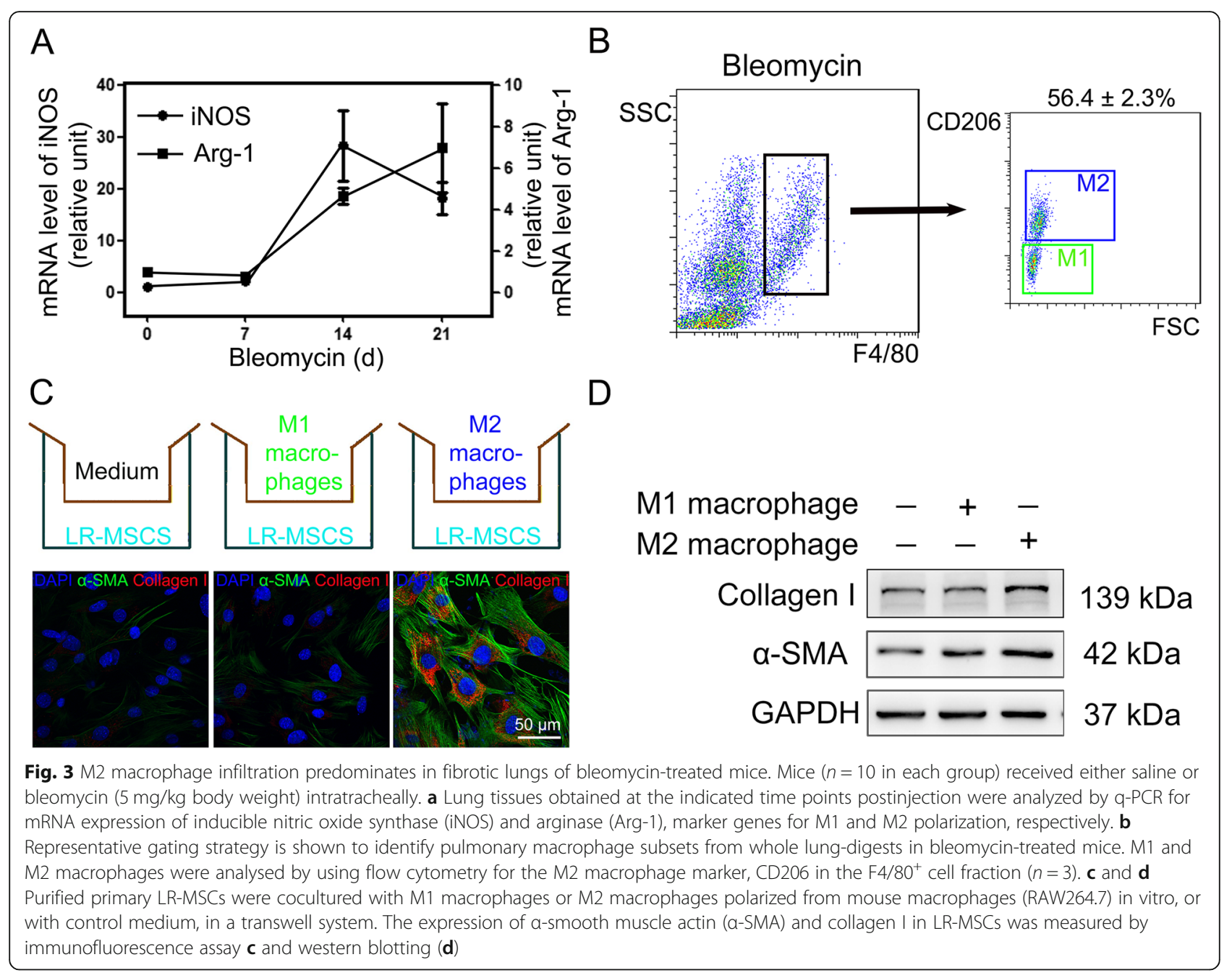

effects on the differentiation of LR-MSCs. To test the functional involvement of M2 macrophages in fibrotic pathology, we first induced macrophage polarization in vitro by using LPS or IL-4 into either M1 or M2 phenotypes, respectively (Additional file 1: Figure S3). Nest, we cocultured M1 macrophages (LPS-stimulated, CD68 ${ }^{+}$ $\mathrm{CCR}^{+} \mathrm{CD} 206^{-}$) or M2 macrophages (IL-4-stimulated, $\mathrm{CD} 8^{+} \mathrm{CCR7}^{-} \mathrm{CD}^{206^{+}}$) with purified primary LR-MSCs in a transwell system (Fig. 3c). After $72 \mathrm{~h}$ coculture, incubation with M1 macrophages did not modulate the differentiation of LR-MSCs. Interestingly, incubation with M2 macrophages dramatically promoted myofibroblast differentiation of LR-MSCs evidenced by the expression of $\alpha$-SMA (Fig. $3 \mathrm{c}$ and d), suggesting that M2 macrophages, rather than M1 macrophages, are able to promote myofibroblast differentiation of LR-MSCs in the pathogenesis of pulmonary fibrosis.

Next, we screened for the candidate factors that may be released from M2 macrophages to affect myofibroblast differentiation of LR-MSCs. The likely candidates were Wnt signaling ligand, which is reported to play important roles both in the differentiation of stem cells and in the development of fibrotic diseases $[45,46]$. Among the numerous factors tested (selected genes shown in Additional file 1: Figure S4), we observed a profound increase of Wnt7a mRNA (Fig. 4a). Moreover, Wnt7a protein was also substantially enriched in the cell culture supernatant of M2 macrophages (Fig. 4b). Consistent with these in vitro data, we further observed an increase in the level of Wnt7a protein in fibrotic lungs and at least some of the Wnt7a expression could be localized to M2 macrophages (Additional file 1: Figure S5 and S6). Using Co-IP we showed the interaction of Wnt7a with Frizzled-1 in LR-MSCs (Fig. 4c and d), which may induce the activation of Wnt/ $\beta$-catenin signaling pathway (Fig. 4e) leading to myofibroblast differentiation of LR-MSCs (Fig. 4f). These data suggest that the canonical Wnt/ $\beta$-catenin signaling pathway in LR-MSCs may be regulated by M2 macrophages in fibrotic lungs.

The Wnt/ $/$-catenin signaling cascade is initiated when a Wnt molecule binds to the frizzled receptor and to the lipoprotein receptor-related protein 5 or 6 (LRP5/6) 


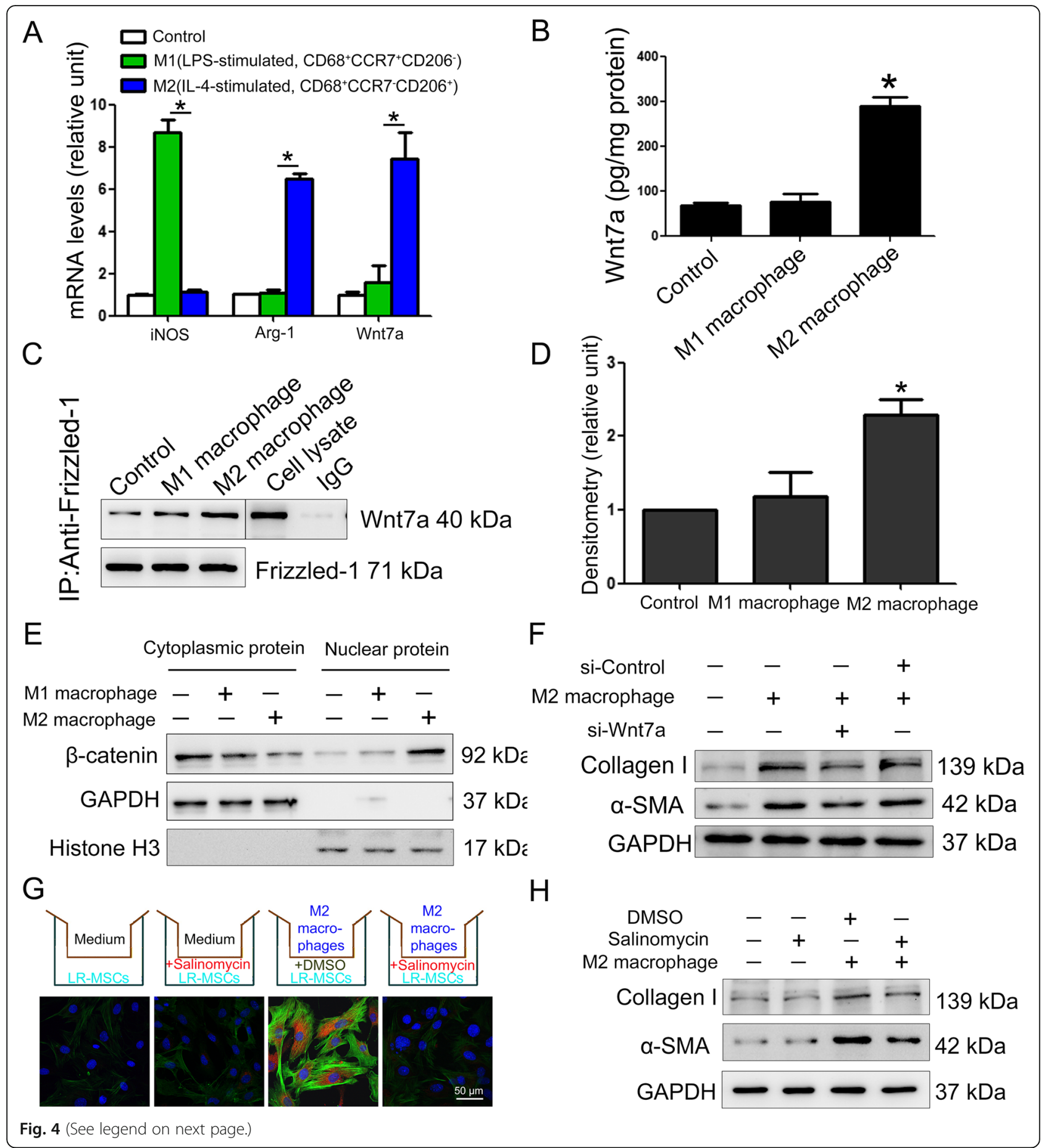




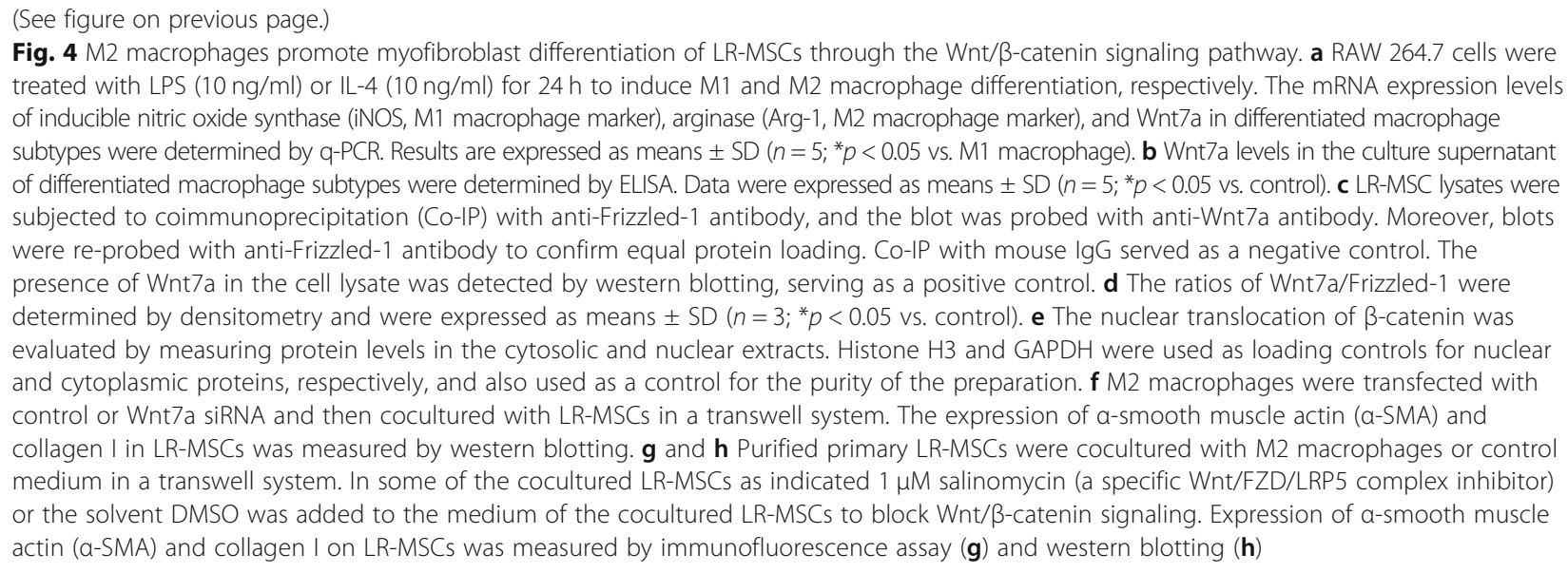

coreceptors, forming a ternary complex at the cell surface. Therefore, we next investigated the effect of Wnt/ $\beta$-catenin signaling on the myofibroblast differentiation of LR-MSCs induced by M2 macrophages using salinomycin which inhibits Wnt/ $\beta$-catenin signaling by acting on the Wnt/Fzd/LRP complex [30]. As expected, salinomycin inhibited the nuclear translocation of $\beta$-catenin (Additional file 1: Figure S7). Notably, the myofibroblast differentiation of LR-MSCs facilitated by M2 macrophages was also profoundly inhibited by salinomycin (Fig. $4 \mathrm{~g}$ and $\mathrm{h}$ ).

\section{Bleomycin-induced pulmonary fibrosis was alleviated by inhibiting the $W n t / \beta$-catenin signaling pathway}

We further explored the effect of $\mathrm{Wnt} / \beta$-catenin signaling on bleomycin-induced pulmonary fibrosis. As shown in Fig. 5a, administration of salinomycin reduced the severity of pulmonary fibrotic lesions and collagen deposition as assessed by H\&E and Masson's trichrome staining. In addition, bleomycin-induced up-regulation of Sca-1, $\alpha$-SMA, and collagen I was also suppressed by salinomycin (Fig. 5b).

\section{Increased infiltration of $\mathrm{M} 2$ macrophages and activation of $\mathrm{Wnt} / \beta$-catenin signaling were observed in the lung tissues of IPF patients}

To verify our findings in clinical samples, we next extended our mouse experiments to the examination of IPF patients. As shown in Fig. 6a, M2 macrophages in human IPF lung tissues outnumbered M1 macrophages, supporting that M2 macrophages might play an important role in human pulmonary fibrogenesis. Moreover, the expression of $\beta$-catenin and Wnt7a was also upregulated, suggesting the activation of Wnt/ $\beta$-catenin signaling in human patients (Fig. 6b). In addition, the colocalization of Wnt7a and M2 macrophages was observed (Fig. 6c).
Taken together, our data highlight a pivotal role of M2 macrophage in the progression of pulmonary fibrosis, possibly by the activating $\mathrm{Wnt} / \beta$-catenin signaling pathway to promote myofibroblast differentiation of LR-MSC (Fig. 7).

\section{Discussion}

Idiopathic pulmonary fibrosis (IPF) is a chronic, progressive lung disease that has a death rate worse than that of many cancers. The pathogenesis of IPF, for which there is still no effective clinical therapy, remains unknown. Recent studies have demonstrated that pulmonary macrophage is involved in the pathogenesis of pulmonary fibrosis [41]. In the current study, we found a substantial infiltration of inflammatory macrophages in fibrotic lungs of bleomycin-treated mice. In a loss-of-function experiment using clodronate to deplete macrophages, we showed that macrophage infiltration is necessary for the development of bleomycin-induced pulmonary fibrosis. It is of note that the alveolar walls of the clodronate-treated group appeared mild degree of fracture and some parts of the fractured alveolar fused, although the severity of pulmonary fibrosis was attenuated. The reason for this phenomenon is probably due to the fact that clodronate injected intratracheally every three days is invasive. This problem can be solved in the future by improving the mode of administration.

Macrophages comprise a heterogeneous population: M1 (classically activated) and M2 (alternatively activated). M1 macrophages are typically associated with inflammation which could have a role in the onset or progression of fibrotic disease; whereas M2 macrophages are involved in matrix deposition and tissue remodeling [47]. Given the complicated heterogeneity in polarization and function of macrophages, it is reasonable to suppose that different subsets of macrophages play different roles in pulmonary fibrogenesis. Here, we showed that M1/M2 ratio inversed from day 14 to day 21 after bleomycin injection, suggesting functional adaptation. Moreover, we used a specific 


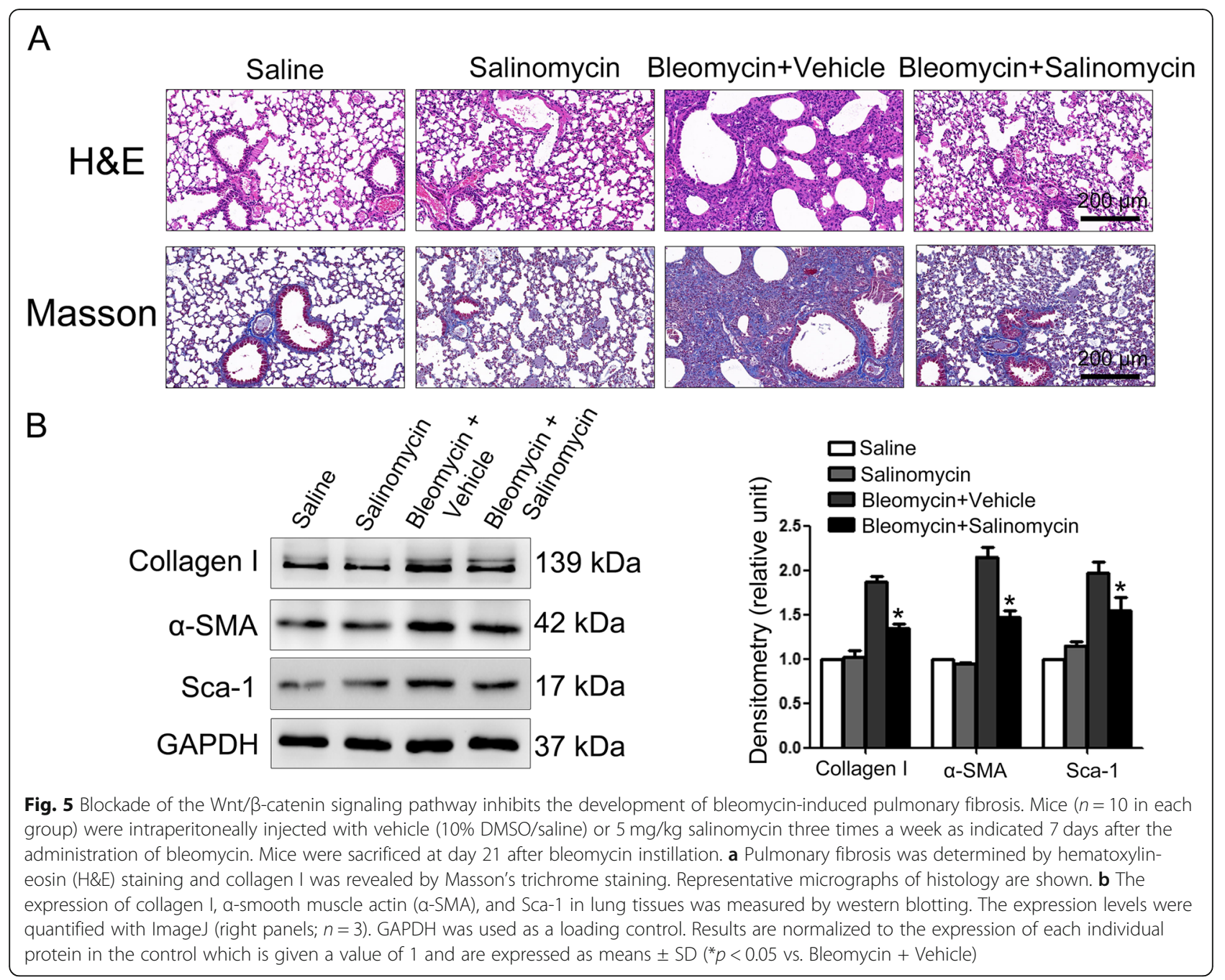

M2 macrophage marker CD206 to differentiate M1 and M2 macrophages by flow cytometry. We found that recruited macrophages in fibrotic lungs are mainly M2 macrophages. These results suggest that a tissue microenvironment rich in M2 macrophages may play an important role in the development of pulmonary fibrosis.

Recent evidence suggests that adult lung tissue contains a population of LR-MSCs that have multiple differentiation potential, and these cells are increasingly recognized as a major source of fibrosis-associated myofibroblasts in pulmonary fibrosis $[9,10]$. The present study observed colocalization of Sca-1 and mesenchymal marker $\alpha$-smooth muscle actin ( $\alpha$-SMA) in lung tissues after bleomycin injection. Our data demonstrated that the myofibroblast differentiation of LR-MSCs occurs during pulmonary fibrogenesis, suggesting that LR-MSCs could play important roles in the development of pulmonary fibrosis.

As the differentiation of LR-MSCs is sensitive to the microenvironment to which these cells are exposed, we set out to investigate the effect of different macrophage subtypes on the differentiation of LR-MSCs. In our study, LPS and IL-4 were used to induce the polarization of M1 and M2 macrophage, respectively. We found that LPS and IL-4 stimulation differentially induced complete M1 and M2 polarization, defined by surface marker expression. Then we established an in vitro Transwell coculture system consisting of activated macrophages and LR-MSCs, and we found that M2, rather than M1 macrophages, can promote the myofibroblast differentiation of LR-MSCs, evidenced by the expression of $\alpha$-SMA. No single marker reliably identifies all myofibroblast, however, $\alpha$-SMA, especially when expressed at a high level, remains a widely recognized marker of myofibroblasts [48]. Although M2 macrophages have been studied for their central role in fibrosis and cell proliferation during tissue repair $[42,49]$, our study provides strong evidence, which was previously unidentified, that they may also have a promoting effect on myofibroblast differentiation of LR-MSCs. 


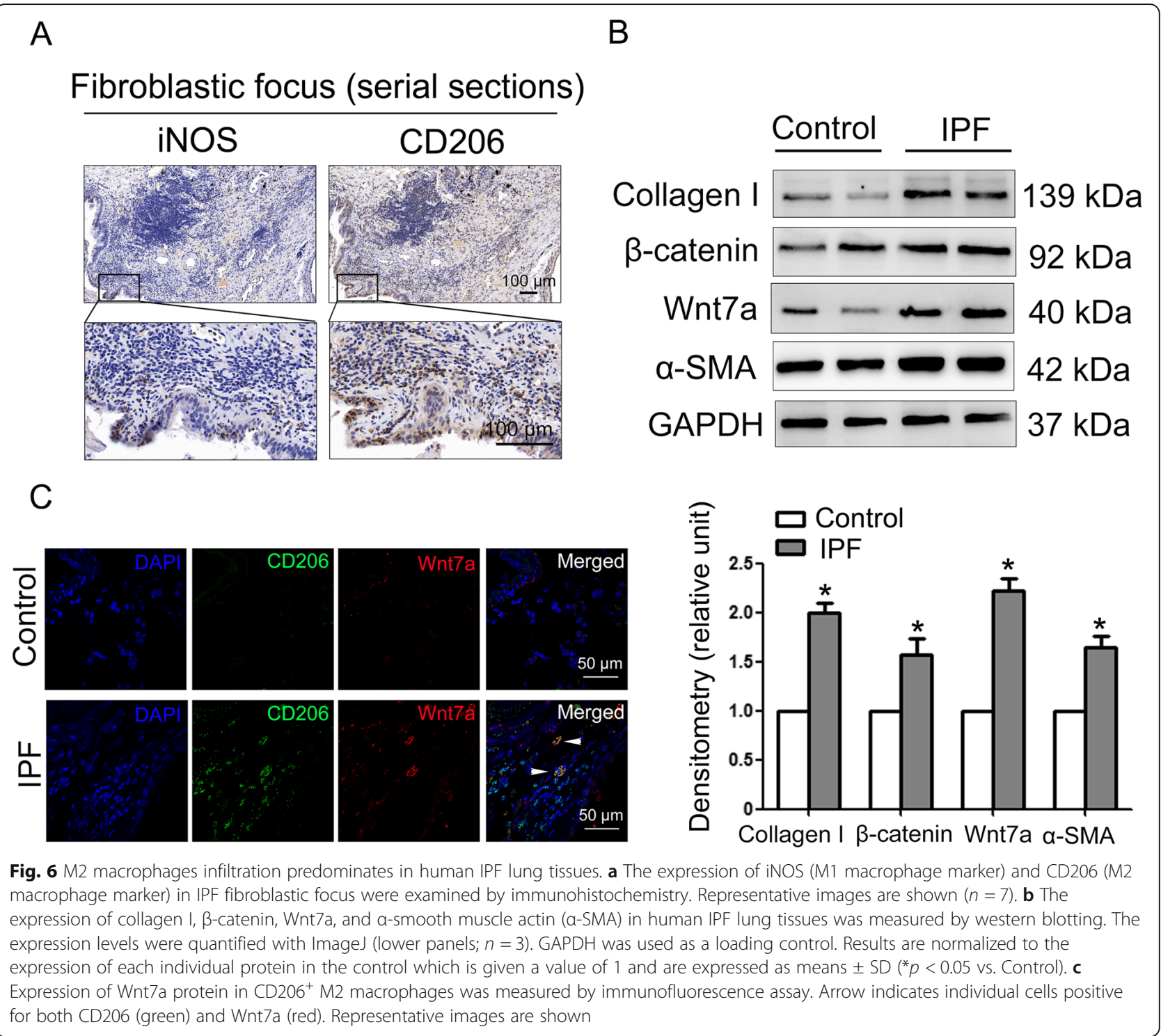

Next, we investigated the possible signaling pathways in LR-MSCs that may be targeted by macrophage-induced LR-MSCs differentiation. The $\mathrm{Wnt} / \beta$-catenin signaling has been extensively implicated in the differentiation of mesenchymal stem cells and progression of fibrotic diseases [50, 51]. Recent studies have shown that macrophage-induced activation of $\mathrm{Wnt} / \beta$-catenin signaling affects the differentiation of hepatic progenitor cells in chronic liver diseases [28]. In this study, we detected a significant increase of Wnt7a protein in fibrotic lungs and specifically in M2 macrophages. M2 macrophages-derived Wnt7a may possibly act on the surrounding LR-MSCs through autocrine or paracrine modes of action. Once Wnt7a binds to the Frizzled-1 of LR-MSCs, the Wnt/ $\mathrm{B}$-catenin signaling pathway can be activated triggering stem cell differentiation [45]. Indeed we observed the activation of Wnt/ $\beta$-catenin signaling in myofibroblast differentiation of LR-MSCs (Fig. 4d). Using Co-IP we showed the interaction of Wnt7a with Frizzled-1 on LR-MSCs, which may induced the nuclear translocation of $\beta$-catenin. Moreover, we demonstrated that inhibition of $\mathrm{Wnt} / \beta$-catenin signaling could suppress the M2 macrophage induced myofibroblast differentiation of LR-MSCs.

Then we investigated the effect of disrupting Wnt/ $\beta$-catenin signaling on bleomycin-induced pulmonary fibrosis. It is generally considered that the lung response after bleomycin has two successive phases: inflammatory phase (day 0 to day 7) and fibrotic phase (day 14 to day 21). To avoid disrupting bleomycin-mediated inflammation which might also be dependent on Wnt/ $\beta$-catenin signaling, we injected salinomycin intraperitoneally 7 days 


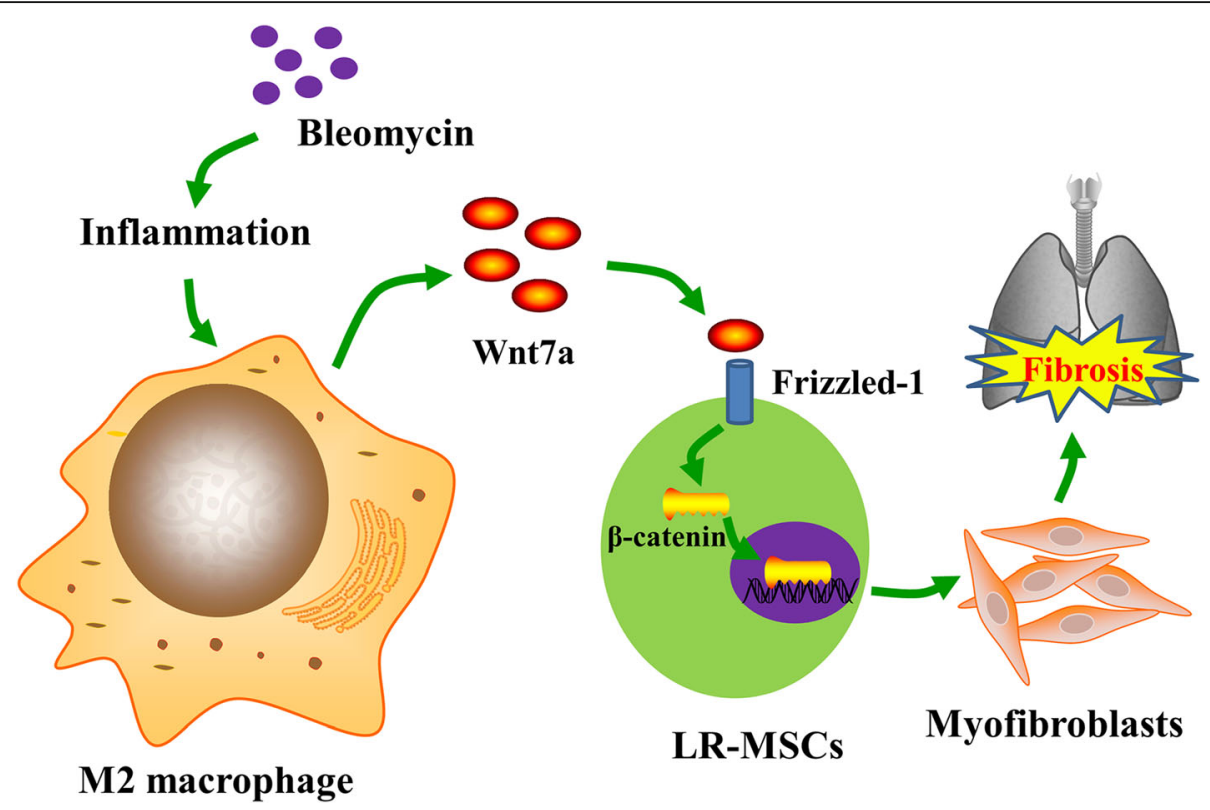

Fig. 7 Schematic representation for hypothetical M2 macrophage-induced myofibroblast differentiation of LR-MSCs. Bleomycin induces severe local inflammation. The recruited M2 macrophages release high levels of Wnt7a, which promotes myofibroblast differentiation of LR-MSCs and pulmonary fibrosis through activating the Wnt/ß-catenin signaling pathway

after bleomycin administration. The results showed that targeted inhibition of $\mathrm{Wnt} / \beta$-catenin signaling by salinomycin protects lungs from bleomycin-induced pulmonary fibrosis. This result was consistent with previous reports [51-54], but in contrast with several reports that have shown that a reactivation of $\mathrm{Wnt} / \beta$-catenin signaling led an attenuation of experimental emphysema [55, 56]. The reason for this discrepancy may result from distinct mechanisms of $\mathrm{Wnt} / \beta$-catenin signaling in the pathogenesis of these two chronic pulmonary diseases, which has been well discussed previously [57].

In addition, it is important to point out that the antifibrotic efficacy of the $\mathrm{Wnt} / \beta$-catenin inhibitor salinomycin may be attributed to other possible mechanisms besides inhibiting myofibroblast differentiation of LR-MSCs. First, another proposed source of fibrotic cells is epithelial cells that undergo epithelial-mesenchymal transition (EMT), a process frequently mediated by TGF- $\beta 1$. Of note, it has been shown that $\mathrm{Wnt} / \beta$-catenin pathway blocking-mediated attenuation of pulmonary diseases was accompanied by a decreased expression of TGF- $\beta 1$ in vivo. These results suggested that salinomycin may exert its antifibrotic action through reducing the expression of TGF- $\beta 1$ and further inhibiting EMT. Secondly, the macrophage M1 - M2 polarization balance may be affected by salinomycin. It has been shown that a coordinate action of various transcription factors, signaling molecules, and inflammatory modulators was involved in regulating macrophage polarization. The presently known molecular determinants of M1 - M2 polarization include members of the STAT, KLF, IRF, PPAR, NF- $\mathrm{kB}$, miRNAs, and HIF families [58].

However, the role of Wnt/ $\beta$-catenin signaling in macrophage polarization still need to be further clarified in future studies.

Furthermore, our analyses of lung tissues from IPF patients suggested that the infiltration of M2 macrophages was increased concomitantly with the activation of $W n t / \beta$-catenin signaling, in agreement with the results from animal model. These results confirmed the clinical significance of our findings and raised the question of the molecular mechanisms that influence the macrophage M1 - M2 polarization balance in pulmonary fibrogenesis.

\section{Conclusions}

To summarize, we discovered that recruited macrophages in fibrotic lungs of bleomycin-treated mice are mainly M2 macrophages. In particular, we found that M2, rather than M1 macrophages, promote myofibroblast differentiation of LR-MSCs through activating Wnt/B-catenin signaling. Thus, our study not only reveals the relationship between macrophages and LR-MSCs in the pathogenesis of pulmonary fibrosis, but also indicates that modulation of macrophage polarization may be a promising treatment for pulmonary fibrosis. Future studies may focus on dissection of the further downstream pathways in LR-MSCs in response to M2 macrophages and definition of the molecular mechanisms that influence macrophage polarization. 


\section{Additional file}

Additional file 1: Table S1. Specifications of primary antibodies. Table S2. Primers used for q-PCR. Figure S1. Pulmonary fibrosis is induced in bleomycin-treated mice. Figure S2. Deletion of macrophages inhibits the expression of inflammatory factors. Figure S3. Cytokine-induced macrophage polarization. Figure S4. M2 macrophages express significant levels of Wnt7a. Figure S5. Bleomycin treatment upregulates Wnt7a, and activates Wnt/ß-catenin signaling in mouse lung tissues. Figure $\mathbf{S 6 . ~ M 2 ~ m a c r o p h a g e s ~ e x p r e s s ~}$ Wnt7a in fibrotic lungs of bleomycin-treated mice. Figure S7. Effects of salinomycin on the nuclear translocation of $\beta$-catenin induced by M2 macrophages in LR-MSCs. (PDF $823 \mathrm{~kb}$ )

\section{Abbreviations}

Arg-1: Arginase; iNOS: Inducible nitric oxide synthase; IPF: Idiopathic pulmonary fibrosis; LR-MSCs: Lung resident mesenchymal stem cells; PBS: Phosphate buffered saline; Sca-1: Stem cell antigen-1; a-SMA: a-smooth muscle actin

\section{Acknowledgements}

The authors are grateful to the National Natural Science Foundation of China for financial supports.

\section{Funding}

This work was supported by the National Natural Science Foundation of China $(81570059,31370524)$ and the Natural Science Foundation of Jiangsu Province of China (BK20151398).

\section{Availability of data and materials}

All data generated during this study are included in this published article and its additional files.

\section{Authors' contributions}

JWH and XDH designed the study and wrote the manuscript, with support from JYS, LC, ZYL, HHC, and XC; JWH, JYS, and XC implemented the in vitro experiments; JWH, LC, ZYL, and HHC performed the in vivo experiments; ZX contributed to data interpretation and manuscript preparation. All authors read and approved the final manuscript.

\section{Ethics approval}

All procedures carried out on animals were approved by the Animal Care and Use Committee of Nanjing University under the animal protocol number SYXK (Su) 2009-0017. All protocols concerning the use of patient samples in this study were approved by the Ethics Committee of Nanjing Drum Tower Hospital.

\section{Consent for publication}

We have obtained consents to publish this paper from all the participants of this study.

\section{Competing interests}

The authors declare that they have no competing interests.

\section{Publisher's Note}

Springer Nature remains neutral with regard to jurisdictional claims in published maps and institutional affiliations.

\section{Author details}

${ }^{1}$ Immunology and Reproduction Biology Laboratory \& State Key Laboratory of Analytical Chemistry for Life Science, Medical School, Nanjing University, Hankou Road 22, Nanjing 210093, China. ${ }^{2}$ Jiangsu Key Laboratory of Molecular Medicine, Nanjing University, Nanjing 210093, China. ${ }^{3}$ Department of Health Technology and Informatics, Faculty of Health and Social Sciences, The Hong Kong Polytechnic University, Hung Hom, Kowloon, Hong Kong, China.
Received: 12 July 2018 Accepted: 13 November 2018

Published online: 23 November 2018

\section{References}

1. Wolters PJ, Collard HR, Jones KD. Pathogenesis of idiopathic pulmonary fibrosis. Annu Rev Pathol. 2014;9:157-79.

2. Raghu G, Collard HR, Egan JJ, Martinez FJ, Behr J, Brown KK, Colby TV, Cordier JF, Flaherty KR, Lasky JA, et al. An official ATS/ERS/JRS/ALAT statement: idiopathic pulmonary fibrosis: evidence-based guidelines for diagnosis and management. Am J Respir Crit Care Med. 2011;183:788-824

3. Raghu G, Weycker D, Edelsberg J, Bradford WZ, Oster G. Incidence and prevalence of idiopathic pulmonary fibrosis. Am J Respir Crit Care Med. 2006;174:810-6.

4. King TE Jr, Pardo A, Selman M. Idiopathic pulmonary fibrosis. Lancet. 2011:378:1949-61

5. Datta A, Scotton CJ, Chambers RC. Novel therapeutic approaches for pulmonary fibrosis. Br J Pharmacol. 2011;163:141-72.

6. Wecht S, Rojas M. Mesenchymal stem cells in the treatment of chronic lung disease. Respirology. 2016;21:1366-75.

7. Hegab AE, Kubo H, Fujino N, Suzuki T, He M, Kato H, Yamaya M. Isolation and characterization of murine multipotent lung stem cells. Stem Cells Dev. 2010;19:523-36.

8. Walker N, Badri L, Wettlaufer S, Flint A, Sajjan U, Krebsbach PH, Keshamouni VG, Peters-Golden M, Lama VN. Resident tissue-specific mesenchymal progenitor cells contribute to fibrogenesis in human lung allografts. Am J Pathol. 2011;178:2461-9.

9. El Agha E, Kramann R, Schneider RK, Li X, Seeger W, Humphreys BD, Bellusci S. Mesenchymal stem cells in fibrotic disease. Cell Stem Cell. 2017;21:166-77.

10. Kramann R, Schneider RK, DiRocco DP, Machado F, Fleig S, Bondzie PA, Henderson JM, Ebert BL, Humphreys BD. Perivascular Gli1+ progenitors are key contributors to injury-induced organ fibrosis. Cell Stem Cell. 2015;16:51-66.

11. Foronjy RF, Majka SM. The potential for resident lung mesenchymal stem cells to promote functional tissue regeneration: understanding microenvironmental cues. Cells. 2012;1:874.

12. Byrne AJ, Mathie SA, Gregory LG, Lloyd CM. Pulmonary macrophages: key players in the innate defence of the airways. Thorax. 2015;70:1189-96.

13. Laskin DL, Sunil VR, Gardner CR, Laskin JD. Macrophages and tissue injury: agents of defense or destruction? Annu Rev Pharmacol Toxicol. 2011;51: 267-88.

14. Misharin AV, Scott Budinger GR, Perlman $H$. The lung macrophage: a Jack of all trades. Am J Respir Crit Care Med. 2011;184:497-8.

15. Schneberger D, Aharonson-Raz K, Singh B. Monocyte and macrophage heterogeneity and toll-like receptors in the lung. Cell Tissue Res. 2011;343: 97-106.

16. Mosser DM, Edwards JP. Exploring the full spectrum of macrophage activation. Nat Rev Immunol. 2008:8:958-69.

17. Murray PJ, Wynn TA. Protective and pathogenic functions of macrophage subsets. Nat Rev Immunol. 2011:11:723-37.

18. Martinez FO, Gordon S. The M1 and M2 paradigm of macrophage activation: time for reassessment. F1000Prime Rep. 2014:6:13.

19. Gordon S, Taylor PR. Monocyte and macrophage heterogeneity. Nat Rev Immunol. 2005:5:953-64.

20. Mantovani A, Sica A, Locati M. Macrophage polarization comes of age Immunity. 2005;23:344-6.

21. Sica A, Mantovani A. Macrophage plasticity and polarization: in vivo veritas. J Clin Invest. 2012;122:787-95.

22. Gordon S, Martinez FO. Alternative activation of macrophages: mechanism and functions. Immunity. 2010;32:593-604.

23. Pechkovsky DV, Prasse A, Kollert F, Engel KM, Dentler J, Luttmann W, Friedrich K, Muller-Quernheim J, Zissel G. Alternatively activated alveolar macrophages in pulmonary fibrosis-mediator production and intracellular signal transduction. Clin Immunol. 2010;137:89-101.

24. Venosa A, Malaviya R, Choi H, Gow AJ, Laskin JD, Laskin DL. Characterization of distinct macrophage subpopulations during nitrogen mustard-induced lung injury and fibrosis. Am J Respir Cell Mol Biol. 2016:54:436-46.

25. Ma ZG, Lv XD, Zhan LL, Chen L, Zou QY, Xiang JQ, Qin JL, Zhang WW, Zeng $\mathrm{ZJ}$, Jin $\mathrm{H}$, et al. Human urokinase-type plasminogen activator gene-modified bone marrow-derived mesenchymal stem cells attenuate liver fibrosis in rats by down-regulating the Wnt signaling pathway. World J Gastroenterol. 2016:22:2092-103 
26. Clevers H, Nusse R. Wnt/beta-catenin signaling and disease. Cell. 2012;149: 1192-205.

27. Saha S, Aranda E, Hayakawa Y, Bhanja P, Atay S, Brodin NP, Li J, Asfaha S, Liu $L$, Tailor $Y$, et al. Macrophage-derived extracellular vesicle-packaged WNTs rescue intestinal stem cells and enhance survival after radiation injury. Nat Commun. 2016;7:13096.

28. Boulter L, Govaere O, Bird TG, Radulescu S, Ramachandran P, Pellicoro A, Ridgway RA, Seo SS, Spee B, Van Rooijen N, et al. Macrophage-derived Wnt opposes notch signaling to specify hepatic progenitor cell fate in chronic liver disease. Nat Med. 2012;18:572-9.

29. Hou J, Ma T, Cao H, Chen Y, Wang C, Chen X, Xiang Z, Han X. TNF-alphainduced NF-kappaB activation promotes myofibroblast differentiation of LRMSCs and exacerbates bleomycin-induced pulmonary fibrosis. J Cell Physiol. 2018;233:2409-19.

30. Lu D, Choi MY, Yu J, Castro JE, Kipps TJ, Carson DA. Salinomycin inhibits Wnt signaling and selectively induces apoptosis in chronic lymphocytic leukemia cells. Proc Natl Acad Sci U S A. 2011;108:13253-7.

31. Zhu L, Fu X, Chen X, Han X, Dong P. M2 macrophages induce EMT through the TGF-beta/Smad2 signaling pathway. Cell Biol Int. 2017:41:960-8.

32. Gordon S. Alternative activation of macrophages. Nat Rev Immunol. 2003;3:23-35.

33. Murray PJ, Allen JE, Biswas SK, Fisher EA, Gilroy DW, Goerdt S, Gordon S, Hamilton JA, Ivashkiv LB, Lawrence T, et al. Macrophage activation and polarization: nomenclature and experimental guidelines. Immunity. 2014:41:14-20.

34. Ishizuka EK, Ferreira MJ, Grund LZ, Coutinho EM, Komegae EN, Cassado AA Bortoluci KR, Lopes-Ferreira M, Lima C. Role of interplay between IL-4 and IFN-gamma in the in regulating M1 macrophage polarization induced by Nattectin. Int Immunopharmacol. 2012;14:513-22.

35. Gong X, Sun Z, Cui D, Xu X, Zhu H, Wang L, Qian W, Han X. Isolation and characterization of lung resident mesenchymal stem cells capable of differentiating into alveolar epithelial type II cells. Cell Biol Int. 2014;38:405-11.

36. Lei M, Jiao H, Liu T, Du L, Cheng Y, Zhang D, Hao Y, Man C, Wang F. siRNA targeting mCD14 inhibits TNF-alpha, MIP-2, and IL-6 secretion and NO production from LPS-induced RAW264.7 cells. Appl Microbiol Biotechnol. 2011;92:115-24.

37. Sun Z, Wang Y, Gong X, Su H, Han X. Secretion of rat tracheal epithelial cells induces mesenchymal stem cells to differentiate into epithelial cells. Cell Biol Int. 2012;36:169-75.

38. Chen X, Shi C, Wang C, Liu W, Chu Y, Xiang Z, Hu K, Dong P, Han X. The role of miR-497-5p in myofibroblast differentiation of LR-MSCs and pulmonary fibrogenesis. Sci Rep. 2017;7:40958.

39. White ES, Atrasz RG, Hu B, Phan SH, Stambolic V, Mak TW, Hogaboam CM, Flaherty KR, Martinez FJ, Kontos CD, Toews GB. Negative regulation of myofibroblast differentiation by PTEN (phosphatase and Tensin homolog deleted on chromosome 10). Am J Respir Crit Care Med. 2006;173:112-21.

40. Mai J, Hu Q, Xie Y, Su S, Qiu Q, Yuan W, Yang Y, Song E, Chen Y, Wang J. Dyssynchronous pacing triggers endothelial-mesenchymal transition through heterogeneity of mechanical stretch in a canine model. Circ J. 2015;79:201-9.

41. Byrne AJ, Maher TM, Lloyd CM. Pulmonary macrophages: a new therapeutic pathway in Fibrosing lung disease? Trends Mol Med. 2016;22:303-16.

42. Pollard JW. Trophic macrophages in development and disease. Nat Rev Immunol. 2009;9:259-70.

43. van Rooijen N, van Kesteren-Hendrikx E. Clodronate liposomes: perspectives in research and therapeutics. Journal of Liposome Research. 2002;12:81-94.

44. van Rooijen $\mathrm{N}$, van Nieuwmegen R. Elimination of phagocytic cells in the spleen after intravenous injection of liposome-encapsulated dichloromethylene diphosphonate. An enzyme-histochemical study. Cell Tissue Res. 1984;238:355-8.

45. Van Camp JK, Beckers S, Zegers D, Van Hul W. Wht signaling and the control of human stem cell fate. Stem Cell Rev. 2014;10:207-29.

46. Piersma B, Bank RA, Boersema M. Signaling in fibrosis: TGF-beta, WNT, and YAP/TAZ converge. Front Med (Lausanne). 2015;2:59.

47. Wynn TA, Vannella KM. Macrophages in tissue repair, regeneration, and fibrosis. Immunity. 2016;44:450-62.

48. Shu DY, Lovicu FJ. Myofibroblast transdifferentiation: the dark force in ocular wound healing and fibrosis. Prog Retin Eye Res. 2017;60:44-65.

49. Xiao X, Gaffar I, Guo P, Wiersch J, Fischbach S, Peirish L, Song Z, ElGohary Y, Prasadan K, Shiota C, Gittes GK. M2 macrophages promote beta-cell proliferation by up-regulation of SMAD7. Proc Natl Acad Sci U S A. 2014;111:E1211-20.

50. Kuhl SJ, Kuhl M. On the role of Wnt/beta-catenin signaling in stem cells. Biochimica et Biophysica Acta (BBA) - Bioenergetics. 2013;1830:2297-306.

51. Chilosi M, Poletti V, Zamo A, Lestani M, Montagna L, Piccoli P, Pedron S, Bertaso M, Scarpa A, Murer B, et al. Aberrant Wnt/beta-catenin pathway activation in idiopathic pulmonary fibrosis. Am J Pathol. 2003;162:1495-502.

52. Sucre JMS, Deutsch GH, Jetter CS, Ambalavanan N, Benjamin JT, Gleaves LA, Millis BA, Young LR, Blackwell TS, Kropski JA, Guttentag SH. A shared pattern of beta-catenin activation in bronchopulmonary dysplasia and idiopathic pulmonary fibrosis. Am J Pathol. 2018;188:853-62.

53. Henderson WR Jr, Chi EY, Ye X, Nguyen C, Tien YT, Zhou B, Borok Z, Knight DA, Kahn M. Inhibition of Wnt/beta-catenin/CREB binding protein (CBP) signaling reverses pulmonary fibrosis. Proc Natl Acad Sci U S A. 2010;107: 14309-14.

54. Konigshoff M, Balsara N, Pfaff EM, Kramer M, Chrobak I, Seeger W, Eickelberg O. Functional Wnt signaling is increased in idiopathic pulmonary fibrosis. PLoS One. 2008;3:e2142.

55. Kneidinger N, Yildirim AO, Callegari J, Takenaka S, Stein MM, Dumitrascu R, Bohla A, Bracke KR, Morty RE, Brusselle GG, et al. Activation of the WNT/ beta-catenin pathway attenuates experimental emphysema. Am J Respir Crit Care Med. 2011;183:723-33.

56. Cui W, Zhang Z, Zhang P, Qu J, Zheng C, Mo X, Zhou W, Xu L, Yao H, Gao J. Nrf2 attenuates inflammatory response in COPD/emphysema: crosstalk with Wnt3a/beta-catenin and AMPK pathways. J Cell Mol Med. 2018;22:3514-25.

57. Shi J, Li F, Luo M, Wei J, Liu X. Distinct roles of Wnt/beta-catenin signaling in the pathogenesis of chronic obstructive pulmonary disease and idiopathic pulmonary fibrosis. Mediat Inflamm. 2017;2017:3520581.

58. Wang $\mathrm{N}$, Liang $\mathrm{H}$, Zen $\mathrm{K}$. Molecular mechanisms that influence the macrophage m1-m2 polarization balance. Front Immunol. 2014;5:614.

\section{Ready to submit your research? Choose BMC and benefit from:}

- fast, convenient online submission

- thorough peer review by experienced researchers in your field

- rapid publication on acceptance

- support for research data, including large and complex data types

- gold Open Access which fosters wider collaboration and increased citations

- maximum visibility for your research: over $100 \mathrm{M}$ website views per year

At BMC, research is always in progress.

Learn more biomedcentral.com/submissions 